\title{
Analysis on the Design of Kindergarten Regional Activities from the Moral Perspective
}

\author{
Ling $\mathrm{Yu}^{1, *}$ \\ ${ }^{1}$ Preschool Teaching and Research Section, Xianyang Vocational Technical College, Xianyang, Shanxi, China \\ *Corresponding author. Email: 857092464@qq.com
}

\begin{abstract}
The basic elements of preschool education are preschool teachers, children, educational content and educational environment. Creating a good educational environment not only can develop children's cognitive abilities, but also is essential for children to form healthy personalities. Kindergarten regional activities are an important part of the educational environment. Scientific and reasonable planning of regional activities, teachers effectively carry out various activities, and organically integrate moral elements into activities, can not only achieve social development expectations, but also meet the characteristics of children's physical and mental development, which is a realistic topic that needs to be solved in kindergarten education and teaching, and it is also one of the research problems of preschool education.
\end{abstract}

Keywords: Moral perspective, Kindergarten regional activities, Regional activity design.

\section{INTRODUCTION}

Swiss psychologist Piaget said that children's cognitive development must be obtained through their continuous interaction with the environment, that is, children's development is the result of the active and positive interaction between their individual factors and the surrounding environment. The process of this function is activity, and activity is the foundation and motivation of children's development. For this reason, people try to create a good activity environment for children and provide sufficient opportunities for activities, so that children can learn and grow in activities. Regional activities are exactly the educational form that produced this kind of educational theory and educational needs. This is based on the study that conforms to the law of children's physical and mental development, uses both hands and brain, and explores independently. As a result, children's interest in learning is greatly aroused. Children's learning is no longer "I am required to learn", but "I want to learn". It is active and dedicated learning. Regional activity education presents an ideal learning state. Regional activities create an

*Project: Phased results of Xianyang Vocational Technical College's academic project "Regional Activity Design and Guidance" (Project No.: 2020KCSZ016). educational environment, dividing the classroom into several independent activity areas, and turning the classroom into an activity room. Regional activities can enable children to actively explore and cooperate in learning according to their own interests and needs, learning methods and development levels, independent content and activity partners, and experience happiness, growth and self-confidence.

The advancement of society, the improvement of people's level of understanding, and the changes in the physical and mental development of young children, urgently need early childhood educators to integrate the elements of education of the country, society, and nation from the perspective of social development and individual long-term, and incorporate moral elements into the content and environment of early childhood education, to realize the foundation and enlightenment of early childhood education, and lay a solid foundation for the positive life development of children.

\section{SIGNIFICANCE OF KINDERGARTEN REGIONAL ACTIVITIES}

Regional activities, also called activity area corners, refer to the fact that teachers divide the 
space of the activity room into different areas based on educational goals, activity materials that children are interested in, and activity types, so as to attract children to choose independently and obtain learning and development activities through full interaction with materials, environment, peers, and full play in the activity area.

Regional activities are a kind of autonomous exploration activities for preschool children. This exploration is sometimes a bilateral activity between children and sometimes between teachers and children. It can achieve the following functions:

The first is to enrich knowledge and experience.

The rich and colorful activity content, various forms of activity, and multilateral activity objects deeply attract children to actively participate. Every child can find fun, find partners, experience, and enjoyment here, so that children's life and learning will become happier and more fulfilling. This not only improves the timeliness of education, but also effectively avoids the occurrence of disputes and contradictions caused by children having nothing to do, so that children's life in the kindergarten is civilized and orderly, fulfilling and happy, making the kindergarten a paradise for children to increase their knowledge and acquire various skills.

The second is to cultivate good character and quality.

Children's activities are not only playing, but also games, and also a unique way of learning. To this end, the teachers create an activity environment in a purposeful and planned manner, and release activity materials so that children can choose learning content and activity partners according to their own abilities and wishes in a relaxed and harmonious atmosphere, and actively explore and communicate with each other. Through operation, perception, and experience, the children can learn to learn, learn to live, learn to communicate, feel the joy of learning, gain self-confidence in growth, form a positive learning attitude, and develop a good character and quality.

The third is to realize the harmonious development of body and mind.

The creation of regional activities meets the needs of the development of early childhood education, has changed the traditional education methods, and made up for the shortcomings of traditional education in the training of children's non-intellectual factors and social aspects. The educational concept of "independence, focus, pleasure, and exploration" advocated by the regional activities reflects full respect for children, and focuses on cultivating good learning qualities; pleasure is the experience of good emotions, and exploration is the cradle of innovative consciousness. Regional activities have fundamentally changed the situation of passively receiving education, making early childhood education more optimized, scientific and reasonable, and realizing children's acquisition of knowledge and experience in the educational environment, active learning, independent learning, self-education, and natural development. This form of learning, learning, and play can effectively promote the harmonious development of children's body and mind.

\section{CLASSIFICATION AND FUNCTIONS OF REGIONAL ACTIVITIES}

\subsection{Classification of Regional Activities}

It can be based on the development needs and educational goals of young children to create an integrated education environment, that is, make full use of various educational resources, effectively use the combination of collective, grouping and individual activities, and organize children to make independent choices and cooperative interactions, belonging to discovery-based learning, life and game activities. The areas can be generally divided into language area, art area, science area, construction area, role-playing area, and cultural area. ("Table 1") 
Table 1. Classification of regional activities

\begin{tabular}{|l|l|}
\hline \multicolumn{1}{|c|}{ Creating area } & \multicolumn{1}{c|}{ Main content } \\
\hline Language area & $\begin{array}{l}\text { The teachers should integrate language learning with games, choose content suitable for } \\
\text { children's perception, recognition, reading, description, and writing, and turn the training goals } \\
\text { into vivid and interesting operation activities. Activities such as reading picture book stories, } \\
\text { listening and speaking, recognition and writing, etc. can be carried out in this area. }\end{array}$ \\
\hline Science area & $\begin{array}{l}\text { The field of science is rich in content, everything that children usually come into contact with, } \\
\text { things that are visible and tangible around them, and the "why" raised by children. }\end{array}$ \\
\hline Art area & $\begin{array}{l}\text { The children can be provided with all kinds of art materials according to the needs of the activities } \\
\text { to carry out activities such as painting, handicrafts, and art appreciation. }\end{array}$ \\
\hline Cultural area & $\begin{array}{l}\text { Combining the characteristics of the country, nation and region, select people, things, and things } \\
\text { with national cultural characteristics, national folk customs, and regional typical characteristics } \\
\text { can be chosen, such as national flag, clothing, race, language, environment, etc. }\end{array}$ \\
\hline Construction area & $\begin{array}{l}\text { The children are provided with a variety of construction materials for children to play construction } \\
\text { games, such as building parks, houses, bridges, the Great Wall, etc. }\end{array}$ \\
\hline Cosplay & $\begin{array}{l}\text { According to children's age, interest and life experience, the children can choose different role- } \\
\text { playing materials and design different role-playing areas, such as doll houses, restaurants, barber } \\
\text { shops, small supermarkets, small banks, small supermarkets, etc. }\end{array}$ \\
\hline
\end{tabular}

\subsection{Functions of Typical Regional Activities}

\subsubsection{Language Area}

In this area, the following goals need to be achieved:

- Cultivating children's sensitivity to pictures and words, and improving children's language comprehension with the help of children's books.

- Cultivating children to experience cultural influence, and cultivating good reading interest and habits.

- Promoting the development of children's language expression ability through the combination of language learning and game training.

- Helping children to comprehend the spiritual connotation of children's books and cultivate a positive attitude towards life and a good character.

\subsubsection{Science Area}

In science area, teachers should try their best to realize the objectives such as:

- Helping young children discover and understand natural phenomena, and accumulating scientific knowledge and experience.

- Stimulating children's interest and thirst for knowledge, and cultivating children's observation and inquiry abilities.

- Helping young children think and solve problems and enhance their scientific awareness.
- Cultivating children's scientific spirit to respect science and be brave to explore.

\subsubsection{Culture Area}

Combining the national and regional characteristics of the creation area, the homeland community can be jointly created. Its main functions are as follows:

- Meeting the yearning of children's cognitive culture and helping them accumulate social and cultural experience.

- Cultivating the collectivism of loving partners, home, garden, hometown and patriotism among children.

- Enhancing children's understanding of cultural material forms, spiritual connotations and system expressions, and enhance cultural sensitivity.

\section{SUGGESTIONS FOR} INCORPORATING MORAL ELEMENTS INTO THE DESIGN OF THE KINDERGARTEN AREA ACTIVITIES

The "Guidelines for Kindergarten Education" clearly pointed out that the environment is an important educational resource, and the creation and use of the environment should be used to effectively promote the development of children. The development of young children is achieved in the interaction with the surrounding environment. A good educational environment has a positive effect on the physical and mental development of young children. Therefore, the researchers incorporate moral elements into the creation of the environment, and combine each creation environment with teaching to extend the 
connotation of educational significance. The authors make suggestions from the following three aspects.

The first is to create a garden environment with moral elements. The environment creation of the kindergarten not only has a material environment but also a good interpersonal environment and spiritual atmosphere. From a moral perspective, in the material environment, it is possible to integrate moral cultivation, family and country feelings, cultural cultivation and legal awareness, set up sculptures, prints, cultural corridors, moral characters and stories, do a good job in moral enlightenment education, and achieve an educational environment that "allows every wall to speak". In the humanistic environment, kindergarten teachers establish a correct view of children, and be a guide, organizer and helper of ideological education in educational and teaching activities, establish an equal and harmonious relationship between teachers and children, so that children can learn the correct concepts and ways of getting along with others, and cultivate the collectivistic emotions of loving the garden, class, teacher, loving family and loving partners, helpful ideology and positive outlook on life.

The second is to shape the kindergarten teachers under the moral concept. On the one hand, kindergartens can train kindergarten teachers through various forms such as going out to study, kindergarten-based teaching and research, old and new, so that teachers can recognize the important value of regional activities and development strategies, as well as change teachers' educational concepts, establish a large-scale curriculum ethics, and guide teachers to place regional activities and concentrated activities in an equally important position. Teachers should strengthen their own learning, constantly update their knowledge, improve their ability to carry out regional activities, and provide good conditions for the comprehensive development of children.

Kindergarten teachers must keep in mind the educational goals of Lide Shuren, in the course goals, content selection and teaching methods, to achieve full coverage of moral goals, full process and integration of content. Teachers should use the standards of "Four Haves" as a good teacher as a guide for action, learn the laws of ideological and political education, master the characteristics of children's physical and mental development, and determine the educational goals through self-study, exchanges and discussions, etc. They also should implement these standards by age groups. In accordance with the principle of gradual progress and spiraling upward, the political identity, family and country sentiments, moral cultivation, awareness of the rule of law, cultural cultivation and other aspects are integrated into the education and teaching suitable for children, so that children's moral education should not only be based on the present, but also focus on the future.

The third is to construct regional activities from the perspective of morality

According to the physical and mental characteristics of children of different ages, combined with the characteristics of different seasons and different regions, regional activities with moral themes can be set. Children in small classes develop the ability to adapt to society, that is, adapt to the life and study of the kindergarten. For example, the language area activities with the theme of "Kindergarten is my home", in this area, the teachers can implement the activities such as developing understanding of the kindergarten environment, kindergarten classes, kindergarten teachers, children's partners, etc., so that children can learn to integrate into the collective, learn the correct way to get along with others, and develop good habits of work and rest. The middle class can focus on cultivating children's moral emotions. In the role-playing area, small stories of moral model characters can be told through collective, group or teacher-child cooperation. Children play roles to interpret roles, experience roles and express emotions, and experience moral emotions. The top class cultivates children's exploration ability. They can experience national symbols, national spirit and regional characteristics by building national landmarks such as the Great Wall and regional historic buildings such as bell towers, bridges, castles, etc. in the construction area, to cultivate children's patriotism and hometown feelings.

\section{CONCLUSION}

Kindergarten regional activity design adheres to the "child-oriented" educational philosophy, follows the laws of children's physical and mental development, and adapts to the needs of social development. When designing regional activities, teachers need to pay attention to educational, practical, subtle, long-term, pluralistic and permeable, and organically integrate into the national and regional Taoist cultural literacy and moral awareness, in order to promote the 
comprehensive and healthy development of children's body and mind.

\section{AUTHORS' CONTRIBUTIONS}

This paper is independently completed by Ling Yu.

\section{REFERENCES}

[1] Zhang Xuhui, The Source and Challenge of Kindergarten Regional Activities [J]. Contemporary Family Education, 2020(36), 65-66. (in Chinese)

[2] Fan Yuzhu, Activating the Zone Corner Effectively Carrying out Regional Activities [J]. Learning Weekly, 2017 (9), 197-198. (in Chinese)

[3] Wu Shuang, Shao Xiaopei, On the Development of Kindergarten Regional Activities from the Perspective of Education Quality [J]. Teacher Education Forum, 2016 (10), 38-42. (in Chinese)

[4] Tang Haihan, Analysis on Factors of Effective Regional Activity in Kindergarten: A Questionnaire Survey [J]. Jiangsu Education Research, 2015 (01), 54-57. (in Chinese)

[5] Chen Meiqing, On the Effective Development of Regional Activities in Kindergartens [J]. Time Education, 2018 (06), 201. (in Chinese)

[6] Zhang Xuhui, Sources and challenges of kindergarten regional activities $[\mathrm{J}]$, Contemporary Family Education, 2020 (36),65-66. (in Chinese) 